\title{
Conhecimento em saúde bucal do bebê e expectativa relativa ao pré-natal odontológico: retrato de um município baiano de grande porte
}

\author{
Knowledge in oral health of baby and expectation \\ for prenatal dental care: portrait of a baiana city
}

\author{
Suélem Maria Santana Pinheiro Ferreira \\ Mestre e Doutoranda em Saúde Pública - Instituto de Saúde Coletiva/ \\ Universidade Federal da Bahia (ISC-UFBA). Docente da Universidade do Estado da Bahia (UNEB) \\ Jinária FeRnANDEs Silva \\ Graduanda em Odontologia. Faculdade Independente do Nordeste - FAINOR \\ Rogério VIEIRA SILVA \\ Mestre e Doutorando em Endodontia - Pontifícia Universidade Católica/ \\ Minas Gerais (PUC-MG). Docente da FAINOR. \\ Érica Silva Pinheiro \\ Graduanda em Odontologia. Faculdade Independente do Nordeste - FAINOR \\ LARISsa Dias Batista \\ Graduanda em Odontologia. Faculdade Independente do Nordeste - FAINOR \\ Carolle Gomes Fernandes \\ Graduanda em Odontologia. Faculdade Independente do Nordeste - FAINOR
}

\begin{abstract}
RESUMO
Objetivo: Elucidar conhecimentos e expectativas, com o pré-natal odontológico e a saúde bucal do bebê, de usuárias da Atenção Básica de Vitória da Conquista-BA. Métodos: Realizou-se estudo transversal, com 268 gestantes e puérperas, escolhidas por amostragem de conglomerados de um estágio, definidos como unidades de saúde da rede básica com equipe de saúde bucal. Procedeu-se a coleta de dados com formulário e realizou-se análise descritiva, com frequências absolutas e relativas. Resultados: Predominou a faixa etária entre 20 a 35 anos $(69,4 \%)$, renda familiar entre 1 a 2 salários mínimos $(64,4 \%)$, realização de até três consultas pré-natais $(37,2 \%)$ e consultas odontológicas para apenas $25,3 \%$. Quanto ao prénatal odontológico, $86,1 \%$ julga importante, mas $27,2 \%$ acreditam não poder fazer tratamento odontológico. Sobre uso de chupeta, $59,6 \%$ mostraram-se favoráveis, com início ao nascer $(62,4 \%)$, e retirada até os 12 meses (52,9\%). Quanto à mamadeira, 57,5\% pretendem ofertá-la a partir dos 4 meses e 37,0\% pretendem utilizar até os 24 meses. Com relação à higiene oral do bebê, $54,9 \%$ pretendem utilizar gaze/fralda e apenas $26,8 \%$ relataram início ao nascimento. Conclusões: Apesar da expectativa com o pré-natal odontológico, o conhecimento sobre o mesmo e a saúde bucal do bebê ainda é deficiente em alguns aspectos.
\end{abstract}

Palavras-chave: Gestantes. Atenção Primária à Saúde. Saúde bucal.

\begin{abstract}
Objectives: We seek to elucidate the knowledge and expectations, with prenatal dental care and oral health of the baby, users of basic attention in city of Vitória da Conquista (BA). Methods: Therefore, we conducted a cross-sectional study with 268 pregnant and postpartum women, chosen by cluster sampling from one stage, defined as the basic health unit with team oral health. Data collection was performed with forms and descriptive analysis was performed, with obtaining absolute and relative frequencies. Results: The predominant age group between $20-35$ years $(69,4)$, family income between 1-2 minimum wages,
\end{abstract}


Suélem Maria Santana Pinheiro Ferreira et al.

performing up to three prenatal visits $(37,2 \%)$ and dental appointment to only $25.3 \%$. Regarding prenatal dental care, $86,1 \%$ consider important, but $27.2 \%$ believe that cannot do dental treatment. About pacifier use, $59.6 \%$ were favorable, starting at birth (62.4\%), and withdrawing up to 12 months (52.9\%). In relation to baby bottle, $57.5 \%$ intend to offer it from 4 months and $37.0 \%$ intend to use up to 24 months. With regard to baby oral hygiene, $54.9 \%$ want to use gauze/diaper and only $26.8 \%$ reported from birth. Conclusions: Despite the expectation with prenatal dental care, knowledge about it and the oral health of the baby is still deficient in some respects.

Keywords: Pregnant women. Primary Health Care. Oral health.

\section{INTRODUÇÃO}

Dada às peculiaridades do período gestacional, os cuidados demandados pelo mesmo e o conjunto de alterações que este imprime sobre a mulher, com possíveis implicações sobre o bebê, é imperativo abordar a gestante sob o ponto de vista da integralidade. Para tanto, é necessária a oferta de um elenco de ações, numa perspectiva de rede de atenção, na qual o cuidado vai além do acompanhamento realizado com o médico e enfermeiro, o que requer cuidados com outros profissionais, como o cirurgião dentista, a partir do pré-natal odontológico'.

A demanda para a implantação do pré-natal odontológico nas unidades de saúde, vem referendada por diferentes políticas. Nesse contexto, a estratégia atual "Rede Cegonha", que visa estruturar a atenção à saúde maternoinfantil no Brasil, insere o cirurgião-dentista como profissional necessário ao atendimento básico na gestação. Ademais, elenca atribuições desse profissional que envolve: sensibilização ao pré-natal, amamentação e vacinação; orientações da periodicidade de consultas e estratégias educativas quanto às novas vivências da gestação, cuidados típicos de cada fase e saúde bucal do bebê; avaliação da saúde geral e bucal; identificação de fatores de risco e adequação de meio bucal; tratamento específico, com os cuidados de cada fase gestacional, que eliminem riscos à gravidez e restabeleçam conforto à gestante; atendimento de urgências/emergências; busca ativa de gestantes faltosas; visita domiciliar na gestação e puerpério; suporte à amamentação e cuidados bucais do bebê ${ }^{1}$.

No contexto da Política Nacional de Saúde Bucal, a gestante deve ser encaminhada para acompanhamento odontológico, que inclua atos como, exame de tecidos moles, diagnóstico de lesões de cárie, gengivite e periodontite crônica, considerando sempre a necessidade versus possibilidades de tratamento, orientação sobre possibilidade de atendimento durante a gestação e planejamento de intervenções educativas².

A despeito do que foi dito, ainda há uma resistência cultural em relação à abordagem odontológica da gestante, sob o argumento dos riscos que esta criaria para o bebê e o curso gestacional. ${ }^{3,4}$ Mitos populares que relacionam o sangramento de procedimentos odontológicos, exposição aos raios-X ou o uso de anestésico com risco de má-formação fetal ou aborto, são os principais motivos de afastamento da gestante do atendimento odontológico ${ }^{3}$. Esse contexto tenciona a efetivação do pré-natal odontológico na rotina dos serviços de saúde, o que requer da equipe de saúde bucal um planejamento criterioso dessa linha de cuidado, para conseguir efetivála. Além disso, é importante salientar que essa representação social não é exclusiva da comunidade, mas também incorporada como simbologia de profissionais envolvidos no cuidado pré-natal, como médicos, enfermeiros e o próprio cirurgião-dentista. ${ }^{5}$

A representação social expressa uma forma de conhecimento dos grupos que procede da vida cotidiana, com origem nas relações interpessoais e que vão constituir um conjunto de explicações para fenômenos diversos ${ }^{6}$. Neste ensejo, comportamentos individuais de cuidados à saúde, tanto referentes à procura/adesão aos serviços de saúde e suas ações, quanto relativos à adoção de estilos de vida saudáveis, podem funcionar como 
determinantes do estado de saúde. Todavia, este comportamento é afetado por um conjunto de processos, tanto pessoais, quanto sociais. Apesar do conhecimento sobre quais práticas de saúde adotar para se ter qualidade de vida, os estilos de vida adotados nem sempre vêm ao encontro de comportamentos saudáveis, sobretudo pela influência de crenças, atitudes e comportamentos, gerados por meio de conhecimento que podem ser produzidos através das representações sociais. ${ }^{7}$

Ao considerar, que gestação é o período em que a mulher se encontra mais absortiva a informações relacionadas ao futuro filho, percebe-se que esse é um momento privilegiado para o trabalho de educação em saúde, que representa uma tecnologia importante para promoção da saúde, através da emancipação dos sujeitos e desenvolvimento de habilidades para 0 autocuidado. ${ }^{5} \mathrm{O}$ conhecimento produzido por intervenções educativas, que devem possibilitar a articulação das vivências cotidianas com as informações advindas do campo científico, cria um vínculo entre a ação assistencial e o pensar-fazer cotidiano, que converge para elevação do estado de saúde. ${ }^{8}$

Além do cuidado ao bebê, o cuidado da gestante para consigo mesma, também depende de informações e motivações para que os tabus, medos e ansiedades que envolvem o tratamento odontológico sejam quebrados. Conforme verificado por Moimaz et al $^{9}$, apesar da maioria das gestantes perceberem modificações na sua boca durante a gravidez, grande parte não procurou atendimento odontológico. Os motivos citados para a falta de procura do cirurgiãodentista foram: acreditar que não necessita de atendimento, mitos e crenças, falta de dinheiro, falta de tempo ou vontade, medo, ida ao dentista antes da gravidez, problemas nos postos de saúde, orientação do médico a não tratar e outros. Esses resultados demonstram como o medo, a insegurança e a banalização por parte das gestantes, quanto à necessidade de tratamento dentário, podem influenciar na saúde do binômio mãe-bebê.

Assim, o presente estudo buscou elucidar o conhecimento em saúde bucal do bebê e as expectativas com o pré-natal odontológico, de gestantes e puérperas acompanhadas em Unidades Básicas de Saúde (UBS's) e Unidades de Saúde da Família (USF's), de Vitória da Conquista - BA, entre dezembro de 2013 e maio de 2014.

\section{Métodos}

Trata-se de uma investigação de corte transversal descritiva, com 268 gestantes e puérperas, da cidade de Vitória da Conquista - BA. Essa cidade, segundo dados do IBGE ${ }^{10}$, conta com uma população de 306.866 habitantes, distribuídos em $3.356,886 \mathrm{~km}^{2}$ e possui a sexta maior economia da Bahia, com participação de 2,29\% no Produto Interno Bruto (PIB) estadual. ${ }^{11} A$ atenção básica à saúde de Vitória da Conquista conta com 39 Equipes de Saúde da Família (ESF), dentre as quais 23 estão situadas na zona urbana, e atuam em 14 USF's, e 8 UBS's. Ademais, o município conta com 30 Equipes de Saúde Bucal, das quais 8 encontram-se inseridas nas USF's urbanas, em sua maioria na proporção 1:2 (uma Equipe de Saúde Bucal-ESB para 2 ESF), além disso, todas as 08 UBS's possuem atenção odontológica.

Ao ponderar os aspectos éticos que envolvem as pesquisas com seres humanos, o projeto de pesquisa foi avaliado e aprovado pelo Comitê de Ética em Pesquisa da Faculdade Independente do Nordeste, sob parecer 418.773/2013. Ademais, a concordância das mulheres em participar da pesquisa foi obtida através de Termos de Consentimento Livre Esclarecido, os quais foram lidos e discutidos entre os entrevistadores/entrevistadas e, posteriormente, assinados pelas mesmas, quando demonstraram interesse em participar.

Além disso, realizou-se estudo piloto em 01 USF, com a população de mulheres acompanhadas no pré-natal e puerpério, no período de uma semana, a fim de dar suporte metodológico aos mesmos, minimizar possíveis erros nos questionários e evitar vieses na obtenção dos dados. 
A população de referência para a presente investigação consistiu de mulheres, residentes na zona urbana de Vitória da Conquista, que estiveram sob acompanhamento no pré-natal/ puerpério, em UBS's e USF's, com equipe de saúde bucal, no período de dezembro de 2013 e maio de 2014. A seleção da amostra se deu por amostragem de conglomerados de um estágio, na qual foram sorteadas 05 USF's, onde atuavam 9 ESF's, e 5 UBS's. Inicialmente foram sorteadas as unidades que seriam incluídas, bem como a ordem de entrada de cada uma delas na amostra do estudo, de forma que em cada ciclo de coleta 1 USF e 1 UBS eram incluídas na coleta de dados. $O$ período de coleta em cada ciclo tinha duração de um mês, e durante esse tempo, todas as gestantes e puérperas que procuraram 0 serviço e atendiam aos critérios de inclusão, foram convidadas a participar da pesquisa.

Os critérios de inclusão utilizados foram: residência na zona urbana de Vitória da Conquista; ausência de complicações durante a gestação ou após o parto que impedissem a amamentação; realização de acompanhamento de pré-natal e puerpério em USF ou UBS, com equipe de saúde bucal; aceitação em participar da pesquisa mediante termo de consentimento livre e esclarecido. Ademais, foram excluídas as seguintes situações: mulheres acompanhadas por UBS ou USF da zona rural; recusa de participar do estudo, no curso da pesquisa; mulheres que apresentaram situação judicial que as separaram dos seus filhos (doação do filho, presidiária); mães de crianças que apresentaram problemas de saúde que contraindicaram a amamentação.

Previamente à coleta de dados, foi realizado estudo piloto, visando validar o instrumento de coleta, elucidar deficiências e corrigi-las. O estudo piloto foi realizado em uma USF, com a população de mulheres acompanhadas no prénatal e puerpério, no período de uma semana.

$O$ instrumento para coleta de dados foi aplicado sob a forma de entrevista direta, com perguntas fechadas direcionadas às mulheres pelo entrevistador, o qual realizou o preenchimento do instrumento de coleta de dados, sem interferir nas respostas obtidas - as quais eram objetivas - para minimizar possíveis vieses na pesquisa. Quatro entrevistadoras, devidamente treinadas procederam à coleta dos dados. Inicialmente se obteve os dados gerais para caracterização sociodemográfica (idade, raça/cor, ocupação, renda e escolaridade), da gestação e consultas pré-natais da amostra. Posteriormente questões que abordaram cuidados e aspectos em saúde bucal do bebê (postura da mulher frente a elementos protetores e potenciais riscos) e expectativas com o pré-natal odontológico foram realizadas.

Os dados obtidos foram organizados em bancos, e analisados através do programa estatístico $R$ versão 2.14.0. A análise realizada teve caráter descritivo, para a qual se utilizou medidas de frequência, tendência central e dispersão. Após essa etapa, foi possível categorizá-las, com a utilização dos padrões e pontos de corte estabelecidos na literatura, ou a distribuição das mesmas.

\section{Resultados}

Foram entrevistadas 268 mulheres, incluindo gestantes $(89,7 \%)$, principalmente no terceiro $(42,2 \%)$ e segundo trimestre $(30,8 \%)$, e puérperas $(10,3 \%)$, que atendiam aos critérios de inclusão da pesquisa. Os resultados, sumarizados na Tabela 1, demonstram a predominância de mulheres vinculadas às UBS's $(58,6 \%)$, que funcionam através do Programa de Agentes Comunitários de Saúde (PACS). Ademais, a caracterização social e demográfica aponta como características frequentes na amostra a faixa etária de 20-35 anos $(69,4 \%)$, raça/cor parda autodeclarada $(62,2 \%)$, ocupação "do lar" $(34,1 \%)$ e estudante $(14,0 \%)$, renda familiar entre 1-2 salários $(64,2 \%)$, nível de escolaridade com ensino médio $(41,0 \%)$, embora a maioria demonstrou baixa escolaridade $(52,3 \%$ não concluiu o ensino médio) e situação conjugal como uma união estável não oficializada, definida como "morar junto com o parceiro" (43,4\%). 
Tabela 1: Caracterização sócio-demográfica, de experiência materna anterior, gestacional e de uso do serviço odontológico das gestantes e puérperas. Vitória da Conquista-BA. Brasil. 2013-2014.

\begin{tabular}{|c|c|c|}
\hline VARIÁVEIS & $\mathbf{n}$ & $\%$ \\
\hline \multicolumn{3}{|l|}{ Tipo de estabelecimento $(n=268)$} \\
\hline Unidade Básica de Saúde & 157 & 58,6 \\
\hline Unidade de Saúde da Família & 111 & 41,4 \\
\hline \multicolumn{3}{|l|}{ Faixa Etária (n=268) } \\
\hline$<20$ & 59 & 22,0 \\
\hline $20-35$ & 186 & 69,4 \\
\hline$>35$ & 23 & 8,6 \\
\hline \multicolumn{3}{|l|}{ Raça/cor auto-referida ( $n=267)$} \\
\hline Preta & 54 & 20,2 \\
\hline Parda & 166 & 62,2 \\
\hline Branca & 47 & 17,6 \\
\hline \multicolumn{3}{|l|}{ Profissão/ocupação (n=264) } \\
\hline Do lar & 90 & 34,1 \\
\hline Estudante & 37 & 14,0 \\
\hline Doméstica & 21 & 8,0 \\
\hline Vendedora & 17 & 6,4 \\
\hline Cabeleireira & 8 & 3,0 \\
\hline Outros $^{1}$ & 91 & 34,5 \\
\hline \multicolumn{3}{|l|}{ Renda Familiar $(n=267)$} \\
\hline$<1$ salário & 70 & 26,1 \\
\hline 1-2 salários & 172 & 64,2 \\
\hline 3-5 salários & 25 & 9,3 \\
\hline \multicolumn{3}{|l|}{ Escolaridade $(n=266)$} \\
\hline Ensino médio & 109 & 41,0 \\
\hline $\begin{array}{l}\text { Ensino fundamental } \\
\text { incompleto }\end{array}$ & 71 & 26,7 \\
\hline Ensino fundamental & 63 & 23,7 \\
\hline Superior incompleto & 10 & 3,8 \\
\hline Superior completo & 8 & 3,0 \\
\hline Não estudou & 5 & 1,9 \\
\hline \multicolumn{3}{|l|}{ Situação conjugal ( $n=267)$} \\
\hline União consensual & 116 & 43,4 \\
\hline Casada & 93 & 34,8 \\
\hline Solteira & 53 & 19,9 \\
\hline
\end{tabular}

\begin{tabular}{|c|c|c|}
\hline Divorciada & 4 & 1,5 \\
\hline Viúva & 1 & 0,4 \\
\hline \multicolumn{3}{|c|}{ Número de Filhos ( $\mathrm{n=267)}$} \\
\hline Até 2 filhos & 123 & 46,1 \\
\hline Nenhum & 108 & 40,4 \\
\hline 3-4 filhos & 30 & 11,2 \\
\hline$>=5$ filhos & 6 & 2,2 \\
\hline \multicolumn{3}{|c|}{ Quantidade de filhos que já amamentou ( $n=265)$} \\
\hline Nenhum & 127 & 47,9 \\
\hline Até 2 filhos & 114 & 43,0 \\
\hline 3-4 filhos & 19 & 7,2 \\
\hline$>=5$ filhos & 5 & 1,9 \\
\hline \multicolumn{3}{|c|}{ Idade gestacional $(\mathrm{n}=\mathbf{2 6 3})$} \\
\hline $1^{\circ}$ Trimestre & 44 & 16,7 \\
\hline $2^{\circ}$ Trimestre & 81 & 30,8 \\
\hline $3^{\circ}$ Trimestre & 111 & 42,2 \\
\hline Puerpério & 27 & 10,3 \\
\hline
\end{tabular}

Número de consultas de pré-natal realizadas $(n=266)$

$\begin{array}{lcc}\text { Nenhuma } & 20 & 7,5 \\ 1-3 \text { consultas } & 99 & 37,2 \\ 4-5 \text { consultas } & 85 & 32,2 \\ \text { >=6 consultas } & 62 & 23,3\end{array}$

Contato com o dentista na gestação $(n=268)$

$\begin{array}{lccc}\text { Não teve contato } & 200 & 74,6 \\ \text { Unidade de Saúde } & 36 & 13,4 \\ \text { Consultório particular } & 30 & 11,2 \\ \begin{array}{lcc}\text { Unidade de saúde } \\ \text { consultório particular }\end{array} & 2 & 0,7\end{array}$

${ }^{1}$ Inclui agente comunitário de Saúde, administradora, ajudante de cozinha, atendente, autônoma, auxiliar administrativa, auxiliar de classe, auxiliar financeira, auxiliar de pessoal, auxiliar de produção, babá, balconista, biscoiteira, bordadeira, caixa, camareira, comerciante, confeiteira, costureira, cozinheira, cuidadora, desempregada, diarista, doceira, empacotadeira, escovista, garçonete, lavadeira, manicure, merendeira, pedagoga, professora, recepcionista, sacoleira, salgadeira, secretaria, serviços gerais, supervisora, técnica de enfermagem, vendedora e vigilante

Sobre a experiência materna anterior, observou-se que frequentemente foi relatado 
possuir até dois filhos $(46,1 \%)$ ou não possuir nenhum $(40,4 \%)$, além de ausência de experiência em amamentação para $47,9 \%$ e amamentação de até dois filhos em $43,0 \%$. Quanto a experiência de acompanhamento pré-natal atual, para a maior parte houve de 1 a 3 consultas $(37,2 \%)$ ou entre 4 e 5 consultas $(32,2)$, e $7,5 \%$ até o momento não havia realizado nenhuma consulta. Além disso, 74,6\% das mulheres não obtiveram nenhum contato com o dentista durante a gestação. (Tabela 1).

Nas tabelas 2 e 3 , estão caracterizados conhecimentos e opiniões sobre o prénatal odontológico e a saúde bucal do bebê. Quando questionadas sobre a necessidade do cirurgião-dentista no acompanhamento prénatal $86,1 \%$ responderam afirmativamente, enquanto $13,9 \%$ relataram ser desnecessária a ação deste profissional. Além disso, a maioria demonstrou compreender que o tratamento odontológico pode ser executado durante a gestação (72,8\%), contra $27,2 \%$ que acreditam não ser possível. Embora, haja essa postura entre as entrevistadas, dentre aquelas que citaram ser necessária a participação do cirurgião-dentista no pré-natal, frequentemente houve desconhecimento das ações que caberiam ao pré-natal odontológico $(46,3 \%)$, seguido da descrição de apenas ações preventivas como limpeza e flúor $(19,6 \%)$, e, uma parte ainda relata que nenhum procedimento odontológico deve ser realizado durante a fase pré-natal $(6,2 \%)$ (Tabela 2$)$.

Quando indagadas sobre, ao menos, três vantagens do aleitamento materno, a maioria não soube relatar $(61,9 \%)$ e tais vantagens foram de conhecimento de apenas $38,1 \%$. Em adição, apenas $20,7 \%$ das mulheres pretendem estender a duração do aleitamento após o primeiro ano de vida, e 5,6\% pretendem oferecê-lo sobre livre demanda. Por outro lado, a exclusividade do aleitamento foi remetida pela maioria $(76,4 \%)$ com duração entre 4-6 meses de vida, e apenas $5,2 \%$ pretendem
Tabela 2: Conhecimentos e expectativas de gestantes e puérperas sobre o pré-natal odontológico. Vitória da Conquista-BA. 2013-2014.

\begin{tabular}{l|c|c}
\hline VARIÁVEIS & N & $\%$ \\
\hline $\begin{array}{l}\text { Opinião da participação do dentista no pré- } \\
\text { natal (n=267) }\end{array}$ & & \\
\hline Julga importante & 230 & 86,1 \\
\hline Não é importante & 37 & 13,9 \\
\hline & & \\
\hline $\begin{array}{l}\text { Opinião sobre possibilidade de tratamento } \\
\text { odontológico durante a gestante (n=268) }\end{array}$ & & \\
\hline Pode ser realizado & 195 & 72,8 \\
\hline Não pode ser realizado & 73 & 27,2 \\
\hline $\begin{array}{l}\text { Ações que o dentista deve desenvolver } \\
\text { durante o pré-natal (n=225) }\end{array}$ & & \\
\hline Educação em saúde & 12 & 5,3 \\
\hline Prevenção (profilaxia, flúor) & 44 & 19,6 \\
\hline Tratamento & 35 & 15,6 \\
\hline $\begin{array}{l}\text { Tratamento com ressalvas (exceto } \\
\text { cirurgia, canal, anestesia) }\end{array}$ & 12 & 5,3 \\
\hline Nenhum procedimento & 10 & 4,4 \\
\hline Qualquer procedimento & 14 & 6,2 \\
\hline Não sabe & 98 & 46,3 \\
\hline & & \\
\hline
\end{tabular}

iniciar a adição de alimentos já nos três primeiros meses de vida (Tabela 3 ).

Tabela 3: Conhecimentos e expectativas de gestantes e puérperas sobre a saúde bucal do bebê. Vitória da Conquista-BA. 2013-2014.

\begin{tabular}{l|c|c}
\hline VARIÁVEIS & $\mathbf{n}$ & $\%$ \\
\hline $\begin{array}{l}\text { Conhecimento de 3 vantagens do } \\
\text { aleitamento (n=257) }\end{array}$ & & \\
\hline Sim & 98 & 38,1 \\
\hline Não & 159 & 61,9 \\
\hline $\begin{array}{l}\text { Quando pretende oferecer outros } \\
\text { alimentos além do leite materno } \\
\text { (n=268) }\end{array}$ & & \\
\hline 0-3 meses 4-6 meses & 14 & 5,2 \\
\hline 7-12 meses & 205 & 76,4 \\
\hline$>13$ meses & 39 & 14,7 \\
\hline Não sabe & 2 & 0,7 \\
\hline
\end{tabular}




\begin{tabular}{|c|c|c|}
\hline $\begin{array}{l}\text { Por quanto tempo pretende amamentar } \\
(n=267)\end{array}$ & & \\
\hline 0-3 meses & 4 & 1,5 \\
\hline 4-6 meses & 89 & 33,2 \\
\hline $7-12$ meses & 97 & 36,2 \\
\hline 13-24 meses & 48 & 18,0 \\
\hline $25-48$ meses & 7 & 2,7 \\
\hline Livre demanda & 15 & 5,6 \\
\hline Não sabe & 7 & 2,6 \\
\hline \multicolumn{3}{|l|}{$\begin{array}{l}\text { Conhece perigos da mamadeira e } \\
\text { chupeta }(n=266)\end{array}$} \\
\hline Sim & 114 & 42,9 \\
\hline Não & 152 & 57,1 \\
\hline \multicolumn{3}{|l|}{ Pretende dar chupeta $(n=267)$} \\
\hline $\operatorname{Sim}$ & 159 & 59,6 \\
\hline Não & 108 & 40,4 \\
\hline \multicolumn{3}{|l|}{$\begin{array}{l}\text { Horário que pretende ofertar a chupeta } \\
(n=153)\end{array}$} \\
\hline Dia & 9 & 5,9 \\
\hline Noite & 56 & 36,6 \\
\hline Dia e noite & 22 & 14,4 \\
\hline Durante o choro & 66 & 43,1 \\
\hline \multicolumn{3}{|l|}{$\begin{array}{l}\text { Com quantos meses pretende dar a } \\
\text { chupeta }(n=157)\end{array}$} \\
\hline Ao nascer & 98 & 62,4 \\
\hline 0-3 meses & 39 & 24,8 \\
\hline 4-6 meses & 11 & 7,0 \\
\hline$>7$ meses & 5 & 3,1 \\
\hline Não sabe & 4 & 2,5 \\
\hline \multicolumn{3}{|l|}{$\begin{array}{l}\text { Ate quando pretende ofertar a chupeta } \\
\text { ao bebê }(n=157)\end{array}$} \\
\hline Até 6 meses & 21 & 13,4 \\
\hline 7-12 meses & 83 & 52,9 \\
\hline 13-24 meses & 26 & 16,6 \\
\hline$>25$ meses & 9 & 5,7 \\
\hline Até a erupção dos dentes & 2 & 1,3 \\
\hline Livre demanda & 8 & 5,1 \\
\hline Não sabe & 8 & 5,1 \\
\hline Pretende dar mamadeira $(n=267)$ & & \\
\hline
\end{tabular}

\begin{tabular}{|c|c|c|}
\hline Sim & 220 & 82,4 \\
\hline Não & 47 & 17,6 \\
\hline \multicolumn{3}{|l|}{$\begin{array}{l}\text { Com quantos meses dar mamadeira } \\
(n=219)\end{array}$} \\
\hline Ao nascer & 11 & 5,0 \\
\hline 1-3 meses & 32 & 14,7 \\
\hline 4-6 meses & 126 & 57,5 \\
\hline$>7$ meses & 43 & 19,6 \\
\hline Não sabe & 7 & 3,2 \\
\hline \multicolumn{3}{|l|}{$\begin{array}{l}\text { Quando interromper o uso da } \\
\text { mamadeira }(n=219)\end{array}$} \\
\hline Até 6 meses & 8 & 3,6 \\
\hline 7-12 meses & 62 & 28,3 \\
\hline $13-24$ meses & 81 & 37,0 \\
\hline$>25$ meses & 32 & 14,6 \\
\hline Livre demanda & 15 & 7,3 \\
\hline Não sabe & 21 & 9,6 \\
\hline \multicolumn{3}{|l|}{$\begin{array}{l}\text { Como pretende fazer higiene bucal do } \\
\text { bebe }(n=264)\end{array}$} \\
\hline Não é necessário & 17 & 6,4 \\
\hline Gaze/fralda & 145 & 54,9 \\
\hline Escova de dente & 22 & 8,3 \\
\hline Escova de silicone & 37 & 14,0 \\
\hline Outro & 43 & 16,3 \\
\hline \multicolumn{3}{|l|}{ Quando iniciar a higiene oral $(n=265)$} \\
\hline Ao nascer & 71 & 26,8 \\
\hline 1-3 meses & 60 & 22,6 \\
\hline 4-6 meses & 40 & 15,1 \\
\hline 7-12 meses & 25 & 9,4 \\
\hline $13-24$ meses & 4 & 1,5 \\
\hline$>25$ meses & 3 & 1,1 \\
\hline Não sabe & 23 & 8,7 \\
\hline Quando erupcionar os dentes & 31 & 11,7 \\
\hline Outros & 8 & 3,0 \\
\hline
\end{tabular}

O perigo do uso de bicos artificiais, quer com finalidade nutritiva ou não nutritiva, não fez parte do conhecimento da maioria das mulheres $(57,1 \%)$. Ademais, $59,6 \%$ das gestantes pretendem ofertar a chupeta para a criança, na maior parte das vezes durante o choro $(43,1 \%)$ ou a noite $(36,6 \%)$, como 
iniciação da oferta já ao nascer $(62,4 \%)$ e perspectiva de interrupção do uso por volta dos 7 a 12 meses (52,9\%). Quanto à mamadeira, $82,4 \%$ pretende oferta-la à criança, com início do seu uso por volta dos $4-6$ meses $(57,5 \%)$ e, interrupção por volta de 12 a 24 meses, em $37 \%$ dos casos (Tabela 3 ).

Por fim, apenas 6,4\% acreditam ser desnecessária a realização de higiene oral do bebê e a maior parte (54,9\%) pretende realizá-la com a utilização de gaze ou fralda. Além disso, quanto ao momento oportuno para início da higiene oral, apenas $26,8 \%$ relatou que a mesma deve ser iniciada logo após o nascimento.

\section{Dıscussão}

Os achados preliminares desse estudo demonstram que embora as mulheres tenham expectativas quanto ao acompanhamento odontológico durante a gestação, ao reconhecer a importância do cirurgião-dentista na fase gestacional, na prática o pré-natal odontológico ainda está distante de maioria das mulheres, que demonstraram ausência de qualquer tipo de contato com o cirurgião-dentista, seja através de consultas individuais ou através de ações de promoção da saúde, por meio de grupos operativos. Nesse sentido, na literatura os fatores que interferem no acesso e adesão de gestantes à atenção odontológica têm sido os fatores psicológicos, incluindo ansiedade, medo, mitos e crenças; dificuldades de acesso à rede de serviços e baixa percepção de necessidade. ${ }^{12}$

Nessa pesquisa, as mulheres estiveram em fases já avançadas da gestação, ou até mesmo já na fase de acompanhamento puerperal, o que deveria possibilitar um maior conhecimento e experiência sobre o pré-natal odontológico e os cuidados com a saúde bucal do bebê. De acordo com o definido na Política Nacional de Saúde Bucal, as gestantes devem passar por consulta odontológica ao iniciar o prénatal ${ }^{2}$. Além disso, ainda que o conhecimento não resultasse de ações desenvolvidas na gravidez atual, o fato da maioria já ter passado por outras experiências gestacionais, também, poderia sugerir uma percepção mais nítida, já que a mulher teria vivenciado tais experiências em momentos posteriores.

Nesse sentido, para Finkler et al. ${ }^{13} \mathrm{e}$ Garbin et al. $^{14}$, as gestantes mostram-se repletas de dúvidas com relação à saúde bucal e aos cuidados que esta demanda, especialmente no tocante a bebês, devido à falta de conhecimento e o pouco contato com cirurgiões-dentistas, especialmente durante a gestação. Estas mulheres não têm sido orientadas sobre os cuidados com a própria saúde bucal durante a gestação, nem sobre a necessidade de procurar o tratamento odontológico neste período e, muito menos, a respeito da saúde bucal do seu bebê.

Dessa forma, ressalta-se a importância do acompanhamento pré-natal, por parte do cirurgião-dentista, como essencial na promoção da saúde, abordagem de riscos e intervenções em condições patológicas da mãe, inclusive àquelas que podem culminar em desfechos desfavoráveis para gestação, como a periodontite..$^{15,16}$ Ademais, o início da linha do cuidado da criança também se inicia nessa fase, através do preparo da família para lidar com tais aspectos. Nesta perspectiva, cabe ao cirurgiãodentista uma atuação mais efetiva no pré-natal, inclusive com busca ativa de gestantes e manejo do afastamento das mesmas dos serviços de saúde bucal por possíveis mitos e barreiras, relacionados ao atendimento odontológico durante a gravidez. ${ }^{17,18}$

A maioria das mulheres não soube relatar as ações que o cirurgião-dentista desenvolve no acompanhamento da saúde bucal de gestante, através do pré-natal odontológico, ou se contradisse ao afirmar que não podem ser realizadas intervenções odontológicas nessa 
fase, mesmo com a afirmação anterior que seria necessária a participação do cirurgião-dentista no pré-natal. Embora, nossa metodologia não possibilite afirmar uma relação sólida, a não realização de um pré-natal odontológico adequado e integral, pode contribuir para tal desconhecimento. Alguns autores confirmam esses mesmos resultados e relatam que as gestantes, de uma maneira geral, apresentam mitos e crenças que envolvem o atendimento odontológico na gravidez e os possíveis danos ao bebê, o que faz com que muitas delas não busquem o atendimento odontológico nesta fase. ${ }^{4,18}$ Outros motivos foram relatados na pesquisa de Albuquerque et al. ${ }^{3}$ entre os quais a falta de interesse, a preguiça, o comodismo, o esquecimento, a indiferença, o fato de não gostar de dentista ou de nem pensar em ir ao dentista durante a gravidez, a baixa valorização da saúde bucal e a baixa apreciação dos resultados do tratamento.

Ainda nesse sentido, a expectativa e conhecimento de gestantes sobre o prénatal odontológico podem sofrer influência da postura dos profissionais, que em algumas situações sentem-se inseguros em prestar assistência adequada as gestantes, e optam pela realização de atendimentos simplificados (profilaxia, palestras educativas, dentre outros) ou procedimentos curativistas, quando estritamente necessários. Esse fato fortalece mitos, agrega novas barreiras e faz com que o atendimento às gestantes nas unidades de saúde, pelos cirurgiões dentistas, seja mínimo, o que não atende a proposta do Programa de Atenção a Saúde da Mulher, nem a Política Nacional de Saúde Bucal. ${ }^{19}$

Sobre a possibilidade de realização de tratamento odontológico, os resultados sugerem um maior esclarecimento da população de estudo, que demonstrou maior confiança e aceitação de tais intervenções na fase gestacional. Entretanto, não se pode ignorar que 1 em cada 4 gestantes ainda possui resistência ao tratamento odontológico, por questões que devem ser trabalhadas pelo profissional da Odontologia através de intervenções educativas baseados na construção compartilhada do conhecimento, o que visa a problematização, reflexão e ação, com respeito à diversidade cultural e o saber popular com a finalidade de obter uma melhoraria a adesão, a segurança e à motivação ao pré-natal odontológico. ${ }^{13,17}$

A discussão sobre a expectativa e o conhecimento de gestantes sobre o pré-natal odontológicotambémseancora na necessidade de apropriação das representações sociais sobre o mesmo, que podem interferir na procura e adesão por serviços e cuidados de saúde. ${ }^{7}$ Além de ferir o direito à informação do usuário do SUS $^{2}$, o desconhecimento da necessidade de realização do acompanhamento odontológico durante a gestação, dificulta a intervenção sobre problemas bucais, predispostos pelas mudanças que a própria gravidez traz, como a cárie ${ }^{20}$ e a doença periodontal, ${ }^{21,22}$ ou ainda pré-existentes. Tais problemas podem reduzir a qualidade de vida da gestante, ou ainda interferir no curso gestacional, como tem sido apontado em relação à doença periodontal, que tem sido relacionada com o parto prematuro e o baixo peso ao nascimento. ${ }^{15,16}$ Além disso, a manutenção da atividade de doenças bucais, dado ao seu caráter infeccioso, pode facilitar a transmissão de microorganismos entre mãe e filho após o parto o que traz riscos à saúde do bebê. ${ }^{23}$

Outro aspecto de interesse nessa pesquisa foi no tocante ao conhecimento sobre saúde bucal do bebê e cuidados inerentes dessa fase. O conhecimento sobre tal aspecto foi avaliado através dos componentes: aleitamento materno, hábitos bucais e higiene oral. Estes juntamente com alterações decorrentes da erupção dentária e alimentação saudável, são definidos pelo Ministério da Saúde como pontos importantes a serem trabalhados com 
gestantes, no contexto da saúde bucal do bebê. ${ }^{24}$

Foram demonstrados os inúmeros benefícios do aleitamento materno para a saúde geral, bem como para o crescimento da face, desenvolvimento das funções do sistema estomatognático e saciedade do impulso de sucção do bebê ${ }^{25}$. Diante disso, é importante estimular, promover e proteger essa prática na atenção pré-natal. Ademais, segundo estudo realizado por Sexton e Natale ${ }^{26}$, o estabelecimento precoce do aleitamento artificial, com o uso de mamadeira pode causar um padrão incorreto da respiração e deglutição. Outro aspecto a se considerar é como o desenvolvimento de hábitos de sucção não nutritiva interrompe o aleitamento materno e provoca prejuízos estruturais e funcionais sobre o sistema estomatognático ${ }^{27}$, além da relativa dificuldade de interrupção dos mesmos.

Quanto a esses aspectos, os achados da presente pesquisa demonstram que a maior parte desconhece a importância do aleitamento materno, os perigos dos bicos artificiais e a época ideal de iniciar a higiene oral da criança. Esse desconhecimento pode contribuir para a alta frequência de gestantes que pretendem ofertar chupetas, inclusive precocemente, quando os efeitos sobre o aleitamento materno, ainda em fase de consolidação, podem ser ainda mais drásticos. ${ }^{28}$ Ademais, a popularidade da mamadeira e a expectativa de interromper a duração do aleitamento materno complementado, antes do período recomendado pela OMS e adotado pelo Ministério da Saúde ${ }^{1}$, podem representar evidências importantes da baixa conscientização identificada nessa pesquisa.

Quanto à higiene oral, deve ser iniciada precocemente, para facilitar à adaptação da criança à manipulação da cavidade oral e, o que consolida o hábito de higienização desde a primeira infância. Esta, deve se iniciar logo após o nascimento, antes mesmo da erupção dos dentes, quando a mãe realiza a higiene oral com gaze, fralda com água filtrada/fervida ou dedeira, para remover resíduos de leite. ${ }^{29}$ Após a erupção dos primeiros dentes na cavidade oral, os pais devem realizar a escovação dental e realizar o uso do fio dental em seus filhos, e orientá-los até que os mesmos estejam aptos a realizar o autocuidado.

Embora tenha sido verificado conhecimento quanto à duração do aleitamento materno exclusivo, forma de higienização bucal do bebê e a expectativa da maioria de interromper o uso da chupeta nos dois primeiro anos, o conhecimento parece descontextualizado ou fruto de processos educativos que não valorizam a reflexão e a emancipação, mas traduzem a prescrição de condutas e comportamentos.

A escassez de conhecimento expressa nos resultados apresentados, também pode guardar relação com as características sociodemográficas nessa amostra que revelam um baixo grau de escolaridade, baixa taxa de ocupação em empregos formais, e renda familiar compatível com a definição grupos sociais "vulneráveis" e "baixa classe média", utilizada pela Secretaria de Assuntos Estratégicos do Governo Brasileiro. ${ }^{30}$ Além disso, a não participação em ações de educação em saúde no pré-natal odontológico podem também contribuir para este cenário.

É importante distinguir, nos estudos em saúde, os indivíduos segundo seu grupo social, já que o processo saúde-doençacuidado não pode ser explicado somente pelos fatores biológicos, uma vez que a qualidade de vida, decorrente dos aspectos sociais, econômicos, políticos e culturais de uma sociedade, é determinante essencial para caracterizar a população inserida Ainda que o contexto social pressione no sentido de haver pouca informação por parte das gestantes, os profissionais que compõem a rede de cuidado pré-natal têm importante papel em minimizar 
tais distorções através da educação em saúde.

Embora algumas pesquisas qualitativas tenham sido executadas sobre a temática ${ }^{5}$ a abordagem epidemiológica pode favorecer o conhecimento da problemática em maior extensão na população. Entretanto, como os dados obtidos foram autodeclarados pelas participantes, é necessário cautela em interpretar algumas informações aqui declaradas.

\section{Conclusão}

Com base nos resultados apresentados, é plausível dizer que as gestantes investigadas demonstraram expectativas com a participação no pré-natal odontológico, embora apresentem conhecimento deficiente sobre seus aspectos operacionais e pouca experiência nessa linha de cuidado. Além disso, embora alguns aspectos que interferem na saúde bucal do bebê demonstraram ser conhecidos pelas gestantes, muitos elementos não são de conhecimento desse grupo específico, que terá o desafio de desempenhar o papel de cuidador de seus filhos.

É imprescindível que o cirurgião-dentista seja bem formado e preparado, para orientar as gestantes e os demais profissionais de saúde, dentro da equipe multidisciplinar, sobre a importância de procedimentos preventivos, a possibilidade de tratamento e aspectos de interesse na saúde bucal da gestante. Ademais, ao considerar que nessa fase a mulher normalmente se encontra mais receptiva as informações, que podem levar à adoção de novas e melhores práticas de saúde, cujos benefícios também se estenderão ao filho e a família, o pré-natal odontológico deve compor a rede de atenção à saúde da gestante.

Por fim, destaca-se que as barreiras no acesso ao serviço odontológico ainda funcionam como um impasse para a aproximação das gestantes aos cuidados de saúde bucal, o que demanda de profissionais e gestores a adoção de estratégias de ampliação do acesso e acessibilidade deste público às ações de saúde bucal.

\section{REFERÊNCIAS}

1 Brasil. Ministério da Saúde. Secretaria de Atenção à Saúde. Departamento de Atenção Básica. Atenção ao pré-natal de baixo risco: Caderno da Atenção Básica n 32. Brasília, DF; 2012.

2 Brasil. Ministério da Saúde. Secretaria de Atenção à Saúde. Departamento de Atenção Básica. Diretrizes da Política Nacional de Saúde Bucal. Brasília, DF; 2004.

3 Albuquerque OMR, Abegg C, Rodrigues CS. Percepção de gestantes do Programa Saúde da Família em relação a barreiras no atendimento odontológico em Pernambuco. Cad Saúde Pública. 2004; 20(3): 789-96.

4 Codato LAB, Nakama L, Melchior R. Percepções de gestantes sobre atenção odontológica durante a gravidez. Cien saude colet. 2008; 13(3): 1075-80.

5 Leal NP, Janotti CB. Saúde bucal da gestante atendida pelo SUS: práticas e representações de profissionais e pacientes. Femina. 2009; 37(8): 413-21.

6 Moscovici, S. A representação social da psicanálise. 1.ed. Rio de Janeiro: Zahar; 1978.

7 Brito AMM, Camargo BV. Representações sociais, crenças e comportamentos de saúde: um estudo comparativo entre homens e mulheres. Temas psicol. 2011; 19(1): 283-303.

8 Brasil. Ministério da Saúde. Secretaria de Gestão Estratégica e Participativa Departamento de Apoio à Gestão Participativa. Cad Ed Popular e Saúde. Brasília, DF; 2007.

9 Moimaz SAS, Rocha NB, Saliba O, Garbin CAS. O acesso de gestantes ao tratamento odontológico. Rev Odontol Univ Sao Paulo (online). 2007; 19(1): 39-45.

10 Instituto Brasileiro de Geografia e Estatística (IBGE). Censo Demográfico 2010: Características da População e dos Domicílios: Resultados do universo. Rio de Janeiro; 2011. 
11 Prefeitura municipal de Vitória da Conquista (PMVC). Cidade: Economia. Vitória da Conquista; 2013. [Acesso: 24 jul. 2014]. Disponível em: http://www.pmvc.ba.gov.br/v2/ economia/.

12 Trevisan CL, Pinto AAM. Fatores que interferem no acesso e na adesão das gestantes ao tratamento odontológico. Arch Health Invest. 2013; 2(2): 29-35.

13 Finkler M, Oleiniski DMB, Ramos FS. Saúde bucal materno-infantil: um estudo de representações sociais com gestantes. Texto \& Contexto Enferm. 2004; 13(3): 360-68.

14 Garbin CAS, Sumida DH, Santos RR, Chehoud KA, Moimaz SAS. Saúde Coletiva: promoção de saúde oral durante a gestação. Rev Odontol UNESP. 2011; 40(4): 161-65.

15 Cruz SS, Costa MCN, Filho ISG, Vianna MIP, Santos CT. Doença periodontal materna como fator associado ao baixo peso ao nascer. Rev Saude Publica. 2005; 39(5): 782-87.

16 Muwazi L,Rwenyonyi CM, Nkamba M, Kutesa A, Kagawa M, Mugyenyi Get al. Periodontal conditions, low birth weight and preterm birth among postpartum mothers in two tertiary health facilities in Uganda. BMC Oral Health. 2014; 14:42

17 Reis DM, Pitta DR, Ferreira HMB, Jesus MCP de, Moraes MEL de. Educação em saúde como estratégia de promoção de saúde bucal em gestantes. Cien saude colet. 2010; 15(1): 269-276.

18 Santos-Neto ET, Oliveira AE, Zandonade E, Leal MC. Acesso à assistência odontológica no acompanhamento pré-natal. Cien saude colet. 2012; 17(11): 3057-68.

19 Martins LO. Assistência odontológica à gestante: percepção do cirurgião-dentista. Rev Pan-Amaz Saude. 2013; 4(4): 11-18.

20 Almeida-Júnior AA, Ramos TM, Novais SMA, Grinfeld S, Fortes TMV, Pereira MAS. Relação Entre a Preferência por Açúcar e a Cárie Dentária em Gestantes do Município de Aracaju-SE. Pesqui Bras Odontopediatria Clin Integr. 2005; 5(1): 59-64.
21 Carrilo-de-Albornoz A, Figueiro E, Herrera $D$, Bascones-Martinéz A. Gingivalis changes during pregnancy: II. Influence of hormonal variations on the subgingival bio film. J Clin Periodontol. 2010; 37: 230-240.

22 Figueiro E, Carrilo-de-Albornoz A, Herrera D, Bascones-Martinéz A. Gingival is changes during pregnancy: I. Influence of hormonal variations on clinical and immunological parameters. J Clin Periodontol. 2010; 37: 220-229.

23 Zaze ACSF, Tondatti CA, Gamberini R, Pfau VJM. Relação de transmissibilidade da microbiota bucal entre pares mães-filhos. Arq. Cienc. Saúde UNIPAR. 2014; 18(3): 145-150.

24 Brasil. Ministério da Saúde. Secretaria de Atenção à Saúde. Departamento de Atenção Básica. Saúde Bucal: Caderno da Atenção Básica n 17. Brasília, DF; 2006.

25 Antunes LS, Antunes LAA, Corvino MPF, Maia LC. Amamentação natural como fonte de prevenção em saúde. Cien saude colet. 2008; 13(1): 103-109.

26 Sexton S, Natale R. Risks and benefits of pacifiers. Am fam physician. 2009; 79(8): 681685.

27 Castilho SD, Rocha MAM. Pacifier habit: history and multidisciplinar view. J pediatr (Rio J.). 2009; 85(6): 480-489.

28 Santos-Neto ET, Zandonade E, Emmerich AO. Modelos de análise dos fatores associados a duração do aleitamento materno. Rev Paul Pediatr. 2013; 31(3): 306-314.

29 Figueiredo MC, Faustino-Silva DD. Efetividade de dedeira de gaze comparada à escova dental convencional no controle do biofilme dentário em bebês. ComScientia Saúde. 2008. 7(3): 357-366.

30 Kamakura WA, Mazzon JA. Estratificação Socioeconômica e Consumo no Brasil. São Paulo: Blucher, 2013.

Submetido em: 02/09/2015

Aceito em: 06/11/2015 